\title{
TÉCNICA CONDUZINDO VIDAS
}

Juliano Carrer ${ }^{1}$

\section{INTRODUÇÃO}

Neste artigo pretende-se dialogar sobre uma possível proposta de ensino Ciência, Tecnologia e Sociedade (CTS) a partir de reflexões do modelo atômico. $\mathrm{Na}$ sociedade atual a técnica é apresentada como salvadora da civilização e as aulas de física acabam contribuindo para isso quando apresentam Ciência e Tecnologia (C\&T) como imutáveis. Nessa lógica deveríamos aceitar os rumos que a humanidade tem seguido na qual a técnica serve a si própria, ataca-se a natureza e geram-se desigualdades. Buscando contribuir para que educandos percebam a mutabilidade da C\&T, é importante que o conhecimento científico seja trabalhado historicamente. Perceber, por exemplo, o átomo tendo seu conceito modificado ao longo da história ajuda a compreender a possibilidade de transformações da própria C\&T, quebrando com a crença de que C\&T são detentoras da verdade absoluta e que podem responder a todos os problemas sociais existentes.

Nesse sentido, existe a necessidade de construir cada vez mais propostas educacionais com uma ideologia diferente da atual, permitindo assim uma sociedade baseada na coletividade, na participação e na autonomia proposta por Freire (1994). Pretende-se ao final do texto colaborar com o debate de uma escola em que educandos ampliem suas percepções entre C\&T e Sociedade ampliando seus papéis de cidadãos na busca de uma técnica a serviço da humanidade. Enfrentando assim o que Postman (1994) chama de Tecnopólio.

\section{O DOMÍNIO DA TECNOLOGIA: SUBJULGAÇÃO DA HUMANIDADE}

Educandos e educadores possuem direito a uma educação libertadora e à criatividade. Infelizmente, a maioria das práticas educacionais tende a desrespeitar essa essência do ser humano. Impedir a criatividade é se opor a possível mudança. $\mathrm{E}$, ignorando a possibilidade de mudança, estamos negando algo próprio à pessoa, o que, logicamente, trata-se de uma educação aprisionadora, cessando a autonomia

\footnotetext{
${ }^{1}$ Universidade do Extremo Sul Catarinense (UNESC) - julianocarrer@gmail.com
} 
e impedindo a felicidade das pessoas. Toda essa postura da escola opressora vem ao encontro de uma ideologia presente na sociedade contemporânea, que Postman (1994) chama de Tecnopólio.

No Tecnopólio a sociedade confere uma crença exagerada à ciência e à tecnologia, aceitando que C\&T definam os rumos que devemos tomar enquanto civilização. Não mais o humano é quem define os rumos da sociedade, mas a técnica. Nesta lógica, somos educados a aceitar o mundo tal como ele é e deixar que continue caminhando sem indagar sobre seus rumos (POSTMAN, 1994).

Neste processo de globalização, no qual a tecnologia é apresentada como a solução para os problemas sociais, despontam cada vez mais aparatos tecnológicos. $E$ alguns até regozijam com esta promessa que surge todos os dias ou quem sabe todas as horas (BAZZO, 2011).

Diante da necessidade de caminharmos frente a essa dominação da técnica sobre o humano, devemos pensar e construir propostas educacionais que verdadeiramente contribuam na educação de cidadãos. Enquanto educadores, um possível caminho talvez seja possibilitar em nossas aulas que educandos ultrapassem a barreira do que Freire (1996) chama de curiosidade espontânea para a curiosidade epistemológica ${ }^{2}$. Essa passagem é impossível sem que a realidade em que vivemos seja refletida em nossas aulas.

Nesse sentido, Postman (1994) sugere como alternativa ao Tecnopólio a importância de não tratar da ciência e da tecnologia como coisas naturais. Assim, a história da humanidade necessitaria ser considerada em nossas aulas. Trabalhar historicamente a construção de determinado conhecimento é importante ideologicamente, pois nos apresenta C\&T como ciências mutáveis. A partir dessa reflexão e da experiência enquanto educador, pretendo refletir sobre o modelo atômico e sua construção histórica. "Ensinar sobre o átomo sem Demócrito [...] é recusar aos nossos estudantes o acesso à Grande Conversa" (POSTMAN, 1994).

"Precisamos "desaprender" que o conhecimento possa ser utilizado reproduzido, construído, repassado - sem que sua natureza seja examinada" (BAZZO; PEREIRA; BAZZO, 2014). Afinal, nas escolas é comum aprendermos e ensinarmos os conteúdos de forma a aparentar que o conhecimento esteja

\footnotetext{
2"a curiosidade ingênua que, "desarmada", está associada ao saber do senso comum, é a mesma curiosidade que, criticizando-se, aproximando-se de forma cada vez mais metodicamente rigorosa do objeto cognoscível, se torna curiosidade epistemológica." (FREIRE, 1996, p. 31).
} 
finalizado. Dessa forma a atuação humana estaria limitada a própria C\&T, pois se não se modifica, se está "pronta e acabada", restaria aos seres humanos segui-la. Sendo então C\&T delimitadoras de opiniões e práticas. Cria-se no imaginário dos alunos a ideologia da imutabilidade freando suas tendências humanas de interferirem nos seus destinos e consequentemente no destino do planeta Terra. Nega-se assim uma característica inerente a C\&T, a de serem construções sociais pela humanidade.

A importância do conhecimento não ser apresentado de forma fragmentada é essencial visto a necessidade dos seres humanos interligarem as particularidades com o todo (MORIN apud BAZZO; PEREIRA; BAZZO, 2014). Trazendo para a produção do conhecimento é essencial que, ao tratarmos de determinados conteúdos em sala de aula, a construção desse conhecimento seja estudada o mais profundamente possível. Não compreender o todo dificultará com certeza que alunos enfrentem situações novas em busca da criação de outras possibilidades. Não é a toa que muitas pessoas treinadas na lógica da dominação da técnica sobre o humano acabem lutando contra as possíveis mudanças que nossa sociedade possa sofrer. Ao se depararem com novidades, ao invés de encará-las em busca de um amadurecimento da humanidade, as ignoram, num pleno sinal de dominação da ideologia atual. Optamos frequentemente por negar a construção de uma nova sociedade, e isto não é a toa, somos treinados desde a infância a aceitarmos que o mundo está dado. Para o Tecnopólio não é interessante que se questione a atual realidade.

A partir do momento em que educandos percebem que conhecimento também é construção social isso contribuirá para que percebam que as coisas podem mudar e que a atual sociedade injusta pode ser modificada, transformada. Negar-se a tratar a ciência desta forma histórica é contribuir para a ideologia dominante que destrói o humano em função da técnica.

Outro saber de que não posso duvidar um momento sequer na minha prática educativo-crítica é o de que, como experiência especificamente humana, a educação é uma forma de intervenção no mundo. Intervenção que além do conhecimento dos conteúdos bem ou mal ensinados e/ou aprendidos implica tanto o esforço de reprodução da ideologia dominante quanto o seu desmascaramento. Dialética e contraditória, não poderia ser a educação só uma ou só a outra dessas coisas. Nem apenas reprodutora nem apenas desmascaradora da ideologia dominante. (FREIRE, 1996, p. 98, grifo nosso) 
Quando se opta por trabalhar determinado conteúdo, como o modelo atômico, se faz importante interligá-lo às questões atuais em que vivemos, trazendo assim presente nas aulas o debate de questões políticas e sociais. Discutindo, assim, o conhecimento nas suas conexões com a realidade, que tenta transformar a todos em consumidores em vez de cidadãos.

\begin{abstract}
Estamos ensinando jovens a serem consumidores, não cidadãos. Isso tolhe sua liberdade futura. Para vivermos livremente, necessitamos de conhecimento de mundo. As questões políticas, sociais, enfim, as humanas, não podem apenas tangenciar a educação. Elas são definidoras. Não podem ficar ausentes. Não educamos para o desenvolvimento tecnológico, mas para a civilidade. (BAZZO; PEREIRA; BAZZO, 2014, p. 49)
\end{abstract}

Não podemos abrir mão de nossa humanidade. No Tecnopólio a Tecnologia vai assumindo de tal forma nossas vidas e nossas instituições que sem nos apercebermos estamos lecionando conteúdos sem motivos aparentes, simplesmente porque "assim é que deve ser feito". Colocamo-nos acríticos frente a questionamentos essenciais: Porque ensinar determinado conteúdo? Que questões tratar nas aulas? De quem é o interesse no atual processo de "ensino" onde educandos são transformados em simples depósitos de conteúdo? Por que cada disciplina é responsável por determinado conteúdo? É preciso avançar nos questionamentos para podermos realmente avançar na (re)humanização da sociedade.

Enquanto seres humanos somos seres da coletividade, que nos constituímos no diálogo de nossa vivência. Além do diálogo com aspectos históricos da construção dos conhecimentos que ensinamos é necessário a conversa com os aspectos sociais e políticos. Nesse caminho estaremos contribuindo para ajudar educandos a intervirem na realidade. Se eles entenderem que as coisas mudam e que se relacionam com a realidade poderão decidir por também participarem dessas mudanças, indo contra a atual proposta de educação neoliberal que aprisiona e torna a vida uma fatalidade.

Do ponto de vista de tal ideologia, só há uma saída para a prática educativa: adaptar o educando a esta realidade que não pode ser mudada. $O$ de que se precisa, por isso mesmo, é o treino técnico indispensável à adaptação do educando, à sua sobrevivência (FREIRE, 1996, p. 19). 
Todas essas angustias da escola opressora e as alternativas apontadas têm no movimento CTS um encontro. Nele ciência e tecnologia devem ser construídas a partir de um posicionamento crítico da sociedade, impedindo que C\&T tenham um desenvolvimento livre de questionamentos e permitindo que C\&T estejam a serviço da humanidade em vez de condutoras dela.

É preciso que as propostas de ensino tragam para seus núcleos a discussão de C\&T, bem como a possibilidade de interferirmos em seus rumos. Por isso a importância de que educandos percebam que C\&T se modificam nas relações com o humano e que há possibilidade de mudança.

Contrapondo-se à ideia de que mais C\&T vão, necessariamente, resolver problemas ambientais, sociais e econômicos. Postula-se a necessidade de outras formas de tecnologia. A alternativa não consiste em "mais C\&T", mas "num tipo diferente de C\&T", concebidas com alguma participação da sociedade. (AULER; BAZZO, 2001, p. 2).

Somente quando educandos e educadores perceberem que o mundo pode mudar é que teremos a possibilidade de uma sociedade mais justa e igualitária. E aulas que questionem a atual conjuntura são essenciais nesse processo.

\section{HORIZONTES PARA O ENSINO: RELATO DE EXPERIÊNCIAS}

Tenho experimentado nos últimos anos a busca de uma sequência didática que ultrapasse a percepção de C\&T como imutáveis. Em especial tenho tido um olhar para o ensino do modelo atômico. Os elementos que vou apresentar a seguir surgem de reflexões dessas experiências em sala de aula.

Busco com a proposta a partir do modelo atômico contribuir para que os educandos ampliem suas percepções entre C\&T e Sociedade e que possam perceber que podem interferir nos rumos de C\&T.

Umas das maiores dificuldades no atual processo de ensino aprendizagem talvez seja o conhecimento ser apresentado como algo pronto e acabado. Iniciar com a possibilidade dos alunos construírem modelos científicos, mesmo que com pouco tempo de reflexão por parte deles é permitir que se coloquem no papel de cientistas. Em sala de aula, oriento que escrevam como título 
da aula "Meu Modelo Atômico" e peço que desenhem como imaginam ser o átomo. Quando se permite aos alunos construírem seus modelos atômicos surgem diversas crenças que eles possuem em relação à constituição dos átomos. Em quatro anos que realizo estas atividades nas minhas aulas nenhum aluno demonstrou clareza da impossibilidade da Ciência visualizar um átomo. Mesmo aqueles que brincam mostrando o caderno em branco, ao serem questionados afirmam que deixaram em branco pois o átomo não pode ser visto a olho nu de tão pequeno. Apenas seria possível, para eles, visualizá-lo utilizando microscópios potentes. Evidência essa que corrobora com a ideologia de uma ciência capaz de tudo, desde que com o equipamento correto, presente no imaginário dos alunos. Quando desenham os átomos, desenham a partir de construções que foram realizando ao longo de seu processo formativo e trazem com os desenhos essas influências. Estar aberto a essa conversa com as concepções alternativas que os educandos trazem é essencial inclusive na compreensão de C\&T enquanto construções que dialogam com mais de um cientista e que dialogam com o "erro".

Erro, não és um mal", como diz Bachelard em "A formação do Espírito Científico (1996, p.298). Mas o erro de que ele fala é o erro positivo, o erro normal, o erro útil, parte integrante e inexorável do verdadeiro trabalho intelectual. Esses erros devem ser distinguidos daqueles que não são erros propriamente ditos, fruto de afirmações gratuitas, inconsequentes, sem nenhum esforço de pensamento.

(PEDUZZI, 2011, p.15)

Após construírem seus modelos atômicos eu faço uma breve retomada do modelo atômico pela história e apresento algumas das atuais crenças da ciência referente ao modelo atômico. Um aspecto interessante é que ao apresentar a ideia do átomo enquanto "modelo" e não como se fosse uma "foto" tirada a partir de um super microscópio muitos alunos acabam fazendo questionamentos do tipo: "Então por que nos ensinam isso? Estão mentindo pra gente então? Ensinam algo que nem conseguem ver?". Traz imensa surpresa neles a ideia de que a ciência fala de algo sem "ver", como se crença fosse algo intimamente ligado a religiões e que a ciência seria conhecimento preciso, final, inquestionável. Evidenciando a ideologia de C\&T enquanto criações mecanicistas, detentoras da verdade.

Não que os alunos em geral acreditem que a ciência é dona da verdade absoluta. Mas acreditam que ela pensa dessa forma. O Tecnopólio vai 
então traçando seu caminho deixando cada vez mais distantes educandos da C\&T. Que atração teriam por algo que percebem fugir totalmente da lógica de suas vidas? Se não conseguem entender como se deu a construção de C\&T como podem se sentirem capazes de contribuir nessa construção? Afasta-se assim os educandos da possibilidade de interferirem nos rumos de C\&T.

Outro momento que traz estranheza novamente neles é quando percebem um professor de Física que apresenta uma ciência que se transforma e vai se modificando com a interferência do ser humano. Parece que para eles um defensor da Ciência e Tecnologia teria logicamente que apresentá-la como detentora de uma única verdade.

Tendo trabalhado os modelos atômicos dos educandos, os modelos atômicos a partir da história e refletido um pouco sobre essas construções, por fim nas aulas eu apresento algumas pesquisas atuais da Física Quântica com o $\mathrm{LHC}^{3}$. Nesse momento quando apresento as investigações no LHC pela busca de "pedaços" do átomo, os alunos passam a questionar: "Como podemos ver os pedaços do átomo, professor, se nem conseguimos ver o átomo?". Fica evidente que neste momento já começam a perceber as incertezas também presentes na Ciência e consequentemente a possibilidade desta se modificar.

\section{CONSIDERAÇÕES FINAIS}

Temos um longo caminho na busca do ensino crítico em nossas escolas. Enquanto contribuição na atual realidade fragmentada das disciplinas, na área das Ciências, acredito ser importantíssimo trazer presente em nossas aulas três aspectos:

- Apresentar a mutabilidade e incertezas da C\&T;

- Discutir a interferência da C\&T na Sociedade e vice-versa;

- Apontar para a possibilidade de a sociedade interferir no desenvolvimento de C\&T.

Os três aspectos contribuem para romper com a proposta do Tecnopólio. Entretanto ainda são muitas barreiras para transpor, principalmente nossa própria formação humana dentro dessa ideologia. Não podemos continuar

\footnotetext{
${ }^{3}$ Large Hadron Collider.
} 
permitindo que nossa humanidade seja retirada. É preciso "empreender em favor do homem e não da produção" (BAZZO; PEREIRA; BAZZO, 2014). Não refletir sobre a produção de C\&T é permitir que o Tecnopólio se alastre cada vez com mais força, é retirar das pessoas algo que é por essência delas, a criação de C\&T.

Os sinais de esperança existem e aparecem quando permitimos aos educandos realmente refletirem sobre C\&T. Se em poucas aulas conseguem perceber as incertezas da construção do conhecimento imagine se a escola como um todo fosse trabalhada nesta perspectiva.

Não se objetivou nesse artigo um tratamento extenso de todo o desenvolvimento dos modelos atômicos, o que considero importante, mas optei por focar aqui alguns aspectos ideológicos presentes no tratamento de conteúdos sem a história da C\&T. Entretanto por considerar importante um possível aprofundamento do modelo atômico finalizo sugerindo maior leitura de autores ${ }^{4}$ que tratam dessa história e de seus desenrolares.

\section{REFERÊNCIAS}

AULER, D.; BAZZO, W. A. Reflexões para a implementação do movimento CTS no contexto educacional brasileiro. Ciência \& Educação, v.7, n.1, p.1-13, 2001.

BAZZO, W. A. Ciência, Tecnologia e Sociedade e o contexto da educação tecnológica. 3aㅡ ed. Florianópolis: Universidade Federal de Santa Catarina, 2011.

BAZZO, W. A; PEREIRA, L. T. V; BAZZO, J. L. S. Conversando sobre educação tecnológica. $1^{\text {a }}$ ed. Florianópolis: Universidade Federal de Santa Catarina, 2014.

FREIRE, P. Pedagogia do Autonomia. 34를 ed. São Paulo: Paz e Terra, 1996.

POSTMAN, N. Tecnopólio: a rendição da cultura à tecnologia. São Paulo: Nobel, 1994.

PEDUZZI, L. O. Q. Evolução dos Conceitos da Física. Florianópolis: UFSC/EAD/CED/CFM, 2011.

${ }^{4}$ Como sugestões apontaram os seguintes textos para além das referências deste artigo:

- PEDUZZI, L. O. Q. Do átomo grego ao átomo de Bohr. Publicação interna. Departamento de Física, Universidade Federal de Santa Catarina, 2008.

- PEDUZZI, L. O. Q. Do próton de Rutherford aos quarks de Gell-Mann, Nambu... Publicação interna. Departamento de Física, Universidade Federal de Santa Catarina, 2010.

- FERREIRA, L. M. Atomismo: Um resgate histórico para o Ensino de Química. 170p. Dissertação (Mestrado) - Universidade Federal de Santa Catarina, Florianópolis, 2013. 